\title{
“APESAR DE VOCÊ, AMANHÃ HÁ DE SER OUTRO DIA"? A OPOSIÇÃO À DITADURA MILITAR EM LIVROS DIDÁTICOS DE HISTÓRIA
}

\section{Mauro Cezar CoElHo* JEFFERSON PLERES RIBEIRO E SILVA**}

Resumo: o presente artigo concorre para os estudos sobre a narrativa didática, por meio da análise de conteúdos relativos à ditadura militar, em livros didáticos do Ensino Fundamental, publicados entre os anos 1993 e 2013. Nosso objetivo foi perceber a relação entre o saber veiculado por eles e a produção historiográfica recente, relativa à temática da ditadura. Verificamos que, a despeito dos avanços vividos pela produção didática, desde a introdução dos processos de avaliação, as narrativas didáticas dedicam pouco espaço aos homens e mulheres que se opuseram ao regime. Argumentamos que a distância que as narrativas guardam em relação à produção historiográfica é um indício importante a justificar esse silêncio.

Palavras-chave: Livro didático. Narrativa. Ditadura militar. Historiografia.

\section{"In spite of you, tomorrow will be another day"? Opposition to military dictatorship in history textbooks}

Abstract: the present article competes for the studies on didactic narrative, through analysis of contents related to the Military Dictatorship, in textbooks of Elementary School published between 1993 and 2013. Our objective was to understand the relation between the knowledge conveyed by them and the recent historiographic production related to the thematic of the Dictatorship. We find that, despite the advances made by didactic production since the introduction of evaluation processes, didactic narratives dedicate little space to the men and women who opposed the Military Dictatorship. We argue that the distance that the narratives keep in relation to the historiographic production is an important indication to justify this silence.

Keywords: Textbook. Narrative. Military Dictatorship Historiography.

\footnotetext{
Hoje você é quem manda Falou, tá falado Não tem discussão, não A minha gente hoje anda Falando de lado E olhando pro chão, viu [...] Quando chegar o momento Esse meu sofrimento Vou cobrar com juros, juro Todo esse amor reprimido Esse grito contido Este samba no escuro Eu pergunto a você Onde vai se esconder Da enorme euforia
}

\footnotetext{
* Professor Associado da Universidade Federal do Pará. Doutor em História pela Universidade de São Paulo (USP).

** Licenciado e Bacharel em História pela Universidade Federal do Pará.
} 
Como vai proibir Quando o galo insistir Em cantar Água nova brotando E a gente se amando Sem parar

Apesar de você Amanhã há de ser Outro dia Apesar de Você - Chico Buarque

Dentre as pesquisas que investigam os conteúdos veiculados nos livros didáticos, a ditadura militar ocupa um espaço relevante - a temática, neste caso, cumpre função decisiva. Em muitos aspectos, as questões que Ihe são inerentes dizem respeito ao tempo em que vivemos, de modo que ela guarda potencial de falar mais de perto aos alunos. Além disso, a forma como ela é abordada pelo saber escolar evidencia, de modo muito particular, a relação existente entre os conteúdos históricos e os axiológicos - especialmente no que se refere à formação para a cidadania.

Os rumos dos estudos sobre o modo como os livros didáticos abordam esse período da experiência brasileira são variados. Há pesquisas que analisam as origens da ditadura militar; outras buscam entender a totalidade do período (1964-1985) nas narrativas didáticas; há aquelas que buscam dar conta de eventos específicos, relativos ao período de exceção democrática; há, ainda, as que procuram investigar as representações da ditadura em seu próprio contexto, ou seja, analisando os livros didáticos editados durante o período de vigência do regime militar; outras comparam mudanças e permanências nas narrativas sobre a ditadura em diferentes décadas.

O trabalho de Adjovanes Almeida (2012), por exemplo, voltou-se para o ano de 1968. O autor analisa como os acontecimentos daquele ano aparecem em narrativas didáticas. Esse autor debruçou-se sobre seis livros didáticos, de coleções diferentes, todos publicados durante a década de 1990. A pesquisa relaciona as representações formuladas pelos livros didáticos sobre a ditadura, considerando os conceitos de comemoração e memória. Valesca Almeida (2014), por sua vez, elegeu a luta armada como objeto de sua pesquisa, dentre as diversas formas de oposição à ditadura. A autora selecionou cinco livros didáticos do Ensino Médio com o intuito de perceber como a oposição à ditadura, expressa pela luta armada, aparece nas narrativas didáticas. Valesca suscita a discussão acerca do livro didático como objeto veiculador de memó- 
rias.

Mateus Pereira e Andreza Pereira (2011) buscam entender as formas como as narrativas didáticas apresentam as origens do golpe de 1964. Para este feito, os autores discutem as mudanças do ensino de história no Brasil, desde a década de 1970 até os anos 2000, bem como as mudanças na própria forma de se pensar e entender o Golpe de 1964. Os autores consideraram livros que foram editados entre 1973 e 2005, com o intuito de perceber as mudanças na construção das narrativas didáticas.

Em projeto mais ambicioso, André Barbosa Fraga (2014) analisou nove livros didáticos, editados entre 1985 e 2011, tendo por objetivo perceber as mudanças e as continuidades no manejo deste conteúdo ao longo de três décadas de redemocratização. O autor defende que, no que tange à ditadura, muita coisa mudou nas narrativas didáticas. Para ele, nas décadas de 1980 e 1990, as narrativas apresentavam um viés predominantemente econômico, com pouco espaço para as questões sociais. Já a partir da década de 2010, os livros passam a transformar os dados numéricos a respeito da violência do Estado sobre a população "[...] em pessoas de carne e osso, com nome e sobrenome" (Fraga, 2011, p. 125); destaca, ainda, a preocupação dos autores, nesta década, em contextualizar a ditadura militar brasileira em um quadro mais amplo, a saber: o círculo das ditaduras latino-americanas.

Em uma perspectiva também ambiciosa, Cristina Adelina de Assunção (2009) se preocupou em estudar como a ditadura militar brasileira foi representada em livros didáticos publicados dentro de seu próprio contexto, ou seja, livros editados entre 1964 e 1985. A autora se debruça sobre as representações naqueles livros acerca do governo de João Goulart, do Golpe Militar e dos governos dos generais presidentes. Em diálogo com as fontes, Assunção trabalha não somente a literatura especializada sobre este campo editorial, mas, também, se ampara na análise das leis educacionais vigentes no período, as quais cerceavam a liberdade das publicações didáticas. A autora destaca, ainda, que há mudanças nas edições didáticas após a Abertura. Para Assunção, a distensão política permitiu mais liberdade na escrita das narrativas didáticas sobre o período dos governos militares.

Já Aristeu Castilho da Rocha (2008) realiza um estudo comparativo das representações textuais e imagéticas da ditadura militar nos livros didáticos, divididos em dois grupos: aqueles publicados entre 1967 e 1988 e os que vieram a lume entre 1995 
e 2005. O autor realiza um minucioso tratamento das fontes ao buscar os eventos referentes à ditadura militar presentes nos livros didáticos, bem como os conceitos utilizados pelos autores. O autor ainda analisa as imagens de capa dos livros e as imagens presentes em cada uma das obras, com objetivo de observar mudanças e permanências nas abordagens sobre o tema.

Naturalmente, nenhum destes trabalhos citados esgota os estudos relativos à forma como a ditadura militar é representada nas narrativas didáticas. De igual modo, o nosso também não possui esta pretensão. Buscamos apresentar uma análise que concorra para o crescimento deste debate. Para tanto, oferecemos uma análise dos conteúdos relativos à ditadura militar, em 16 livros didáticos de 8a série ou 9o ano do Ensino Fundamental, publicados entre os anos 1993 e 2013, conforme tabela a seguir.

Tabela 1

\begin{tabular}{|l|c|}
\hline \multicolumn{2}{|c|}{ LIVROS DIDÁTICOS ANALISADOS ${ }^{1}$ - ANO DE PUBLICAÇÃo } \\
\hline Título dos Livros & Publicação \\
\hline História: assim caminha a humanidade 8a série. & 1993 \\
\hline História do Brasil: Império e República, volume 2. & 1995 \\
\hline Brasil: uma história em construção. & 1996 \\
\hline História: passado presente v. 4: a expansão Imperialista e o Brasil República. & 1997 \\
\hline Brasil: para compreender a história, 6a série. & 1997 \\
\hline Brasil: para compreender a história, volume 1. & 1997 \\
\hline História: compreender para aprender, 8. & 1998 \\
\hline Saber e fazer história, 8a série. & 1999 \\
\hline Construindo consciências: história, 8. a série. & 2006 \\
\hline Encontros com a história: 8a série. & 2006 \\
\hline Projeto Araribá: história & 2007 \\
\hline História em documento: imagem e texto, 9o ano. & 2009 \\
\hline Estudar história: das origens do homem à era digital. & 2011 \\
\hline História: sociedade e cidadania 9o ano. & 2012 \\
\hline História nos dias de hoje, 9o ano. & 2012 \\
\hline Projeto Apoema História 9. & 2013 \\
\hline Fonte: Autores (2018).
\end{tabular}

Fonte: Autores (2018).

Todos os livros foram consumidos em escolas públicas da cidade de Belém e, portanto, foram avaliados pelo Programa Nacional do Livro Didático - PNLD. Nosso objetivo foi perceber a relação entre o saber veiculado por eles e a produção historiográfica recente, relativa à temática da ditadura. Verificamos que, a despeito dos avanços vividos pela produção didática, desde a introdução dos processos de avaliação (Mi-

\footnotetext{
${ }^{1}$ As referências completas de cada obra didática citada na tabela encontram-se na seção "Fontes", ao final deste artigo.
} 
randa e Lucca, 2004), o saber histórico referente à ditadura pouco se articula com a produção historiográfica que lhe é relativa.

Assim, a ditadura que emerge das narrativas acaba por contradizer a previsão do poeta. A gente que viveu o período, que se posicionou diante do regime, apoiandoo ou opondo-se a ele, permanece não sendo ouvida. Conforme pretendemos demonstrar, ao considerar como a resistência ao regime vem sendo abordada pelas narrativas didáticas, os homens e mulheres que constituíram outras vozes que não as do poder permanecem caladas. A distância que as narrativas guardam em relação à produção historiográfica é um indício importante a justificar esse silêncio.

\section{Considerações necessárias}

Em análise sobre o modo como a literatura didática aborda a colonização portuguesa na América, Mauro Cezar Coelho (2017) faz algumas considerações sobre o enredo das narrativas didáticas. Para ele, "o enredo organiza a narrativa, emprestando-Ihe coerência e sentido". O enredo pode ser percebido na forma como os eventos são relacionados. No que concerne ao tema que se ocupa naquele texto, o autor defende que a condução das narrativas didáticas é herdeira de uma tradição que se edifica ao longo do século XIX, cuja principal característica consiste na narração da história do Brasil como um desdobramento da história europeia. Helenice Rocha e Flávia Caimi (2014), em estudo anterior, reconhecem que as narrativas didáticas têm experimentado mudanças, mas apontam a preponderância do modelo cronológico e de uma perspectiva linear, na qual a Europa ainda ocupa lugar de destaque como fio condutor nas narrativas presentes nos livros didáticos.

A maneira de narrar é, então, fundamental para a análise da literatura didática, especialmente quando se pretende considerar o conteúdo veiculado por ela. Atentar para a narrativa e para os eventos que a constituem é, pois, tarefa fundamental para a compreensão dos objetivos subjacentes ao texto didático. Diante disso, nos propusemos identificar quais eventos aparecem mais recorrentemente nas narrativas didáticas voltadas para o desvendamento da ditadura militar. Importava saber que conjunto de eventos era acionado, com vistas à conformação do que denominavam de ditadura militar. Nesse sentido, um dado nos foi favorável - o conteúdo relativo à ditadura é 
identificado pelos livros didáticos de modo inequívoco.

Os livros didáticos acionam o processo com o qual nos ocupamos de modo exclusivo - tratando especificamente do caso brasileiro - ou o situam no contexto latinoamericano. Qualquer que seja a forma adotada, os livros sempre identificam a ditadura com um período no qual uma série de eventos transcorre e fornece sentido ao processo histórico tratado. O conjunto de eventos varia, então, de livro a livro. Percebê-los em conjunto, porém, nos permite dar conta não somente dos eventos considerados, mas de certos consensos na escrita histórica escolar sobre a ditadura militar.

As recorrências, nesse sentido, não podem ser pensadas como coincidências, mas como indícios da presença de uma postura compartilhada sobre como se constituem as narrativas didáticas, seus objetivos e, sobretudo (naquilo que interessa ao escopo deste artigo), a relação que o saber escolar mantém com o saber de referência. Os eventos, a perspectiva com que são acionados e o modo como são articulados podem nos indicar como a produção historiográfica é acionada pelos autores das obras didáticas, para além da informação presente nas listas de obras de referência ao final dos volumes. Vejamos, então, que eventos são esses.

Tabela 2

\begin{tabular}{|l|c|l|c|}
\hline \multicolumn{2}{|c|}{ EVENTOS - DITADURA MILITAR } & Coleções \\
\hline Eventos & Coleções & Eventos & 12 \\
\hline “Diretas Já" & 13 & Governo Fernando Collor & 11 \\
\hline Assassinato de Carlos Lamarca & 2 & Governo Fernando Henrique Cardoso & 9 \\
\hline Assassinato de Carlos Marighella & 2 & Governo Itamar Franco & 10 \\
\hline Assassinato de Edson Luís & 4 & Governo Jânio Quadros & 11 \\
\hline Assassinato de Manoel Fiel Filho & 8 & Governo João Batista Figueiredo & 9 \\
\hline Assassinato de Vladimir Herzog & 9 & Governo João Goulart & 13 \\
\hline Ato Institucional no 1 & 11 & Governo José Sarney & 10 \\
\hline Ato Institucional no 2 & 10 & Governo Juscelino Kubitschek & 10 \\
\hline Ato Institucional no 3 & 8 & Governo Vargas & 9 \\
\hline Ato Institucional no 4 & 6 & Lei de Anistia & 2 \\
\hline Ato Institucional no 5 & 15 & Lei de Imprensa & 2 \\
\hline Governo Castelo Branco & 12 & Lei de Segurança Nacional & 7 \\
\hline Governo Costa e Silva & 12 & Lei Falcão & 5 \\
\hline Governo Emílio Garrastazu Médici & 10 & Passeata dos Cem Mil & 16 \\
\hline Governo Ernesto Geisel & 11 & Resistências Armadas & \\
\hline
\end{tabular}

Fonte: Autores (2018).

A tabela 2 reúne os eventos identificados nas dezesseis coleções e a sua inci- 
dência. Na primeira e terceira colunas, arrolamos os eventos, tal como são identificados pelos livros didáticos; na segunda e quarta colunas o número de coleções em que ele é acionado. A tabela indica dois fatores que precisam ser ressaltados. Em primeiro lugar, elas permitem discutir o livro didático como uma obra histórica de natureza complexa. Não nos referimos, aqui, aos fatores recorrentemente acionados pelas análises dos livros didáticos quanto a sua condição de produto cultural, com enorme importância para o mercado do livro e sua posição como suporte curricular para um conjunto imenso de estudantes e professores. ${ }^{2}$ A complexidade a que nos referimos diz respeito ao fato de que o livro didático, como instância operadora do saber histórico escolar, não se constitui como mero reprodutor do saber historiográfico - ele formula narrativas que obedecem a princípios e propósitos próprios, como sugere a diversidade de eventos acionados pelas dezesseis coleções acerca do mesmo processo. Em segundo lugar, a variedade e a variação dos eventos faculta a discussão sobre as opções e caminhos adotados pelas narrativas didáticas, com vistas a propor aos seus leitores estudantes e professores da Educação Básica - uma compreensão do passado para fins didáticos: que eventos constituíram o processo, qual a relação entre eles, qual o sentido que lhes pode ser atribuído e que aprendizado pode ser construído a partir deles.

As duas questões merecem reflexão exclusiva, considerando o processo em questão ou qualquer outro que constitui a narrativa didática. Não nos aprofundaremos, aqui, sobre qualquer uma das duas discussões nesse momento, tendo vista os limites deste artigo, mas consideramos importante situá-las, de modo a deixar claro que a narrativa didática compreende, mais que uma compilação do saber de referência, a proposição de uma interpretação do passado que não é limitada, exclusivamente, pelo saber historiográfico. Voltemos, então, à tabela.

A tabela permite algumas constatações iniciais. A primeira diz respeito aos tipos de eventos - de um lado, as ações do Estado, de outro as ações da sociedade. Salta aos olhos que grande parte das coleções, não apenas acione a ditadura militar por meio dos governos dos presidentes da República (incluindo os que antecederam e os que se seguiram ao regime), mas organize a narrativa por meio das ações destes governos. Assim, a ditadura é narrada a partir das ações dos presidentes - o governo de

\footnotetext{
${ }^{2}$ Ver por exemplo: Ferreira; Franco, 2008, p.79; Horikawa; Jardilino, 2010, p. 147-162; Silva, 2012, p. 803-821; Munakata, 2012, p 51-66; e Zambon; Terrazan, 2013, p. 585-602.
} 
cada um deles, demarcada pelo tempo que estiveram à frente do Executivo - e pelas ações do regime, marcadamente de repressão (atos, leis e assassinatos). A sociedade é protagonista das ações de resistência - a passeata dos Cem Mil, a resistência armada e a campanha pelo retorno das eleições diretas para presidente.

Diante desses grupos de eventos, optamos por analisar dois deles - as ações de repressão do regime e as ações de resistência da sociedade. Ambos são relevantes, pois reúnem pouco mais de $1 / 4$ das remissões aos eventos em todo o conjunto estudado. Tal conjunto de eventos permite perceber como os dois atores principais das narrativas didáticas acerca do regime são acionados, percebidos e concorrem para a conformação do sentido didático das narrativas sobre a ditadura militar. Eles facultam, sobretudo, a análise sobre como a resistência ao regime é abordada pelo texto didático.

Assim, entre as ações de repressão, destacam-se os assassinatos por motivação política de opositores do regime. Nas dezesseis coleções analisadas, 25 vezes o assassinato de diferentes personagens teve papel de destaque na estrutura narrativa, elevando estas mortes à categoria de eventos. Chama atenção que os assassinatos tenham mais importância para a narrativa do que qualquer ação que as personagens tenham realizado em vida e que tenha contribuído para a oposição ao regime. O destaque dado à violência que sofreram e o silêncio sobre as ações que protagonizaram é um indício do lugar das figuras de oposição ao regime nas narrativas: na maior parte dos casos são coadjuvantes de uma trama conduzida por outros.

Entre as ações de oposição ao regime, três eventos são recorrentes. Em menor medida, há referência à Passeata dos cem mil em cinco das dezesseis obras. Em seguida, a Campanha pelas Diretas Já é acionada em treze livros. Por fim, os movimentos de resistência armada (reunidas as resistências armadas urbanas e rurais) constituem a narrativa em todas a dezesseis coleções analisadas. Ao optarem por tais eventos, a narrativa didática silencia sobre outros importantes movimentos de resistência à ditadura. Como exemplo, podemos citar: as lutas dos estudantes que não necessariamente pegaram em armas; segmentos da Igreja Católica que se posicionaram contra o regime; a classe artística, que fez frente ao governo nos seus mais variados segmentos nas artes plásticas (com exposições em locais restritos, mas também com ousadas intervenções de rua), nas letras de música e performances em shows, na literatura, nos 
quadrinhos e charges, e inúmeras outras manifestações; as resistências políticopartidárias (de membros do partido de oposição Movimento Democrático Brasileiro MDB, por exemplo); jornalistas e exilados políticos que, mesmo fora do país, continuaram lutando e se articulando contra o governo. Todas essas manifestações de resistência são referidas em boxes, que compõem o livro didático, mas não estão presentes nas narrativas sobre o processo. Eles cumprem uma função acessória, são aspectos curiosos do regime, não constituem a narrativa histórica propriamente dita.

A seguir nos ocuparemos com a análise de dois daqueles grupos de eventos - a opressão do regime, demarcada pelos assassinatos, e a resistência ao regime, balizada pelos movimentos de massa. Reunidos, eles permitem sopesar como os opositores da ditadura são abordados nas narrativas. Ambos nos permitem concretizar algumas das questões que temos pontuado até aqui: a narrativa didática procede a uma seleção de eventos, por meio dos quais se apropriam de modo particular do saber historiográfico com vistas à consecução dos fins didáticos que dão significado à obra. Iniciemos com as ações de repressão do regime.

\section{Retratos da morte - os opositores do regime}

Os assassinatos de algumas figuras emblemáticas da oposição ao regime militar aparecem 25 vezes no decorrer dos textos principais dos livros didáticos trabalhados, como se pode ver no gráfico abaixo. As pessoas assassinadas pela repressão dão nome e rosto à oposição política do regime. Dentre elas, quem mais se destaca é a figura do jornalista Vladimir Herzog. Sua morte é abordada em nove das dezesseis narrativas didáticas. São inúmeros os trabalhos acadêmicos que evocam a memória de Vlado, como era conhecido. Não se pode dizer, porém, que a frequente evocação de Herzog nas narrativas didáticas, seja reflexo da recorrência das análises em que este é objeto de estudo ${ }^{3}$. Principalmente porque, Carlos Lamarca, capitão do exército que desertou para se tornar guerrilheiro, também é analisado por larga produção acadêmica e, no entanto, em apenas dois livros didáticos seu assassinato foi caracterizado como um evento no enredo da ditadura militar ${ }^{4}$.

\footnotetext{
${ }^{3}$ Sobre Herzog ver, por exemplo: Dantas, 2012; e Markun, 2015.

${ }^{4}$ Sobre Carlos Lamarca ver, por exemplo: José; Miranda, 1989, e Nogueira, 2008, p. 1-28.
} 
Gráfico 1

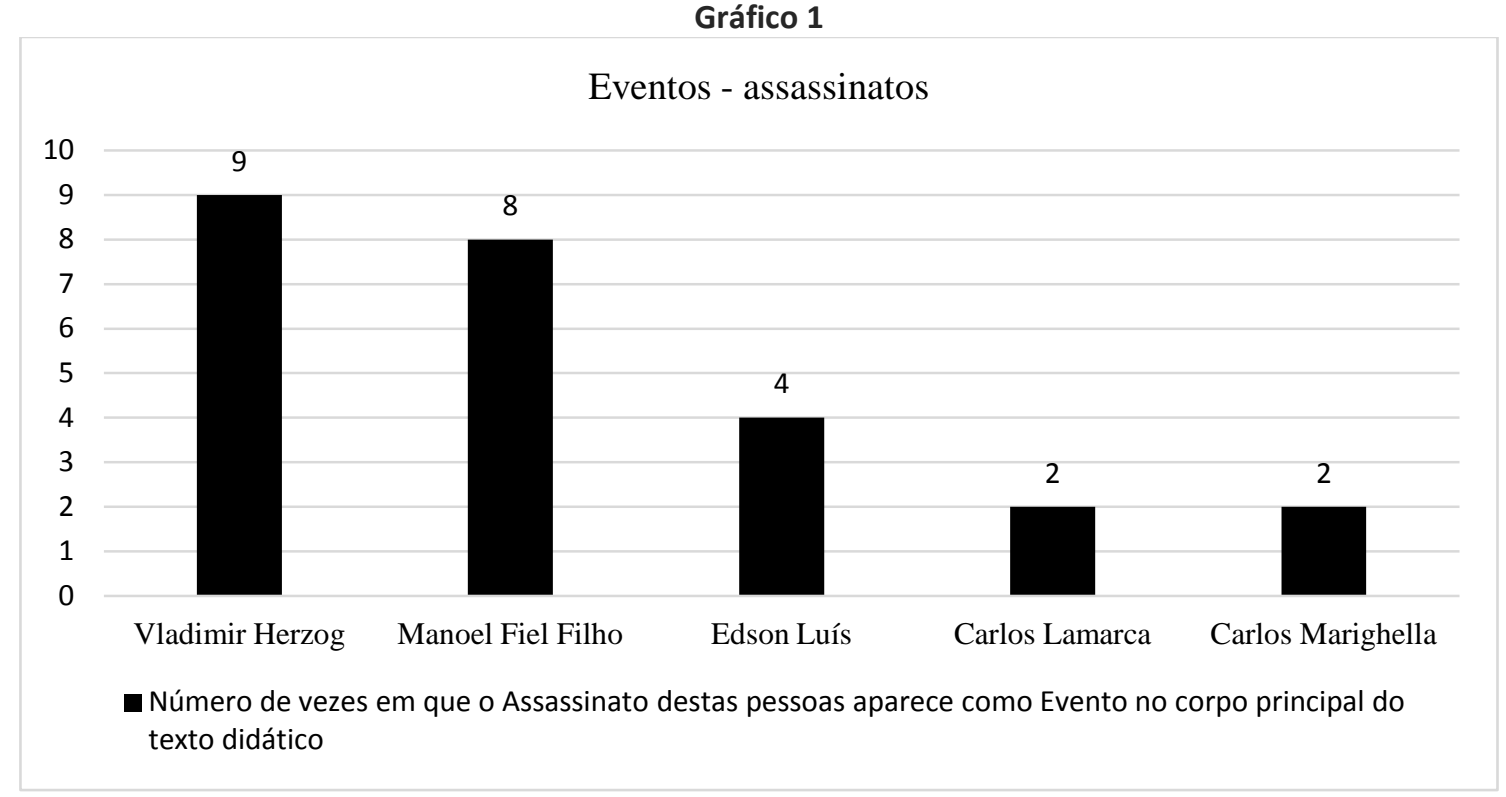

Fonte: Autores (2018).

Antes de prosseguirmos na análise das ações de repressão do regime, outro fator deve ser chamado à discussão: o lugar dos discursos complementares que acompanham a narrativa principal. Consideramos aqui todas as falas que acompanham a narrativa sem, necessariamente, fazer parte dela. Tais discursos são fundamentais, posto permitir o dimensionamento daquela narrativa. São excertos de textos acadêmicos, jornalísticos, letras de músicas etc. Talvez, não seja surpreendente que dentre todos os discursos identificados, a fotografia tenha sido, de longe, o mais encontrado nas páginas dos livros didáticos. Os dados que apresentam a frequência com que cada um destes discursos aparece nas narrativas didáticas podem ser observados no gráfico 2.

O gráfico aponta que a narrativa principal é acompanhada por ilustrações de natureza diversa (desenhos e mapas em grande parte), letras de músicas do cancioneiro popular, reproduções de propagandas veiculadas na imprensa, excertos de matérias jornalísticas, tabelas com informações relacionadas à temática abordada no texto principal, reproduções de charges, excertos de textos acadêmicos e fotografias. Verificamos que, apesar da variedade de suportes discursivos, há grande diferença na incidência de cada tipo, com destaque para o número de vezes em que fotografias são acionadas. Elas superam todos os outros suportes somados. 
Gráfico 2

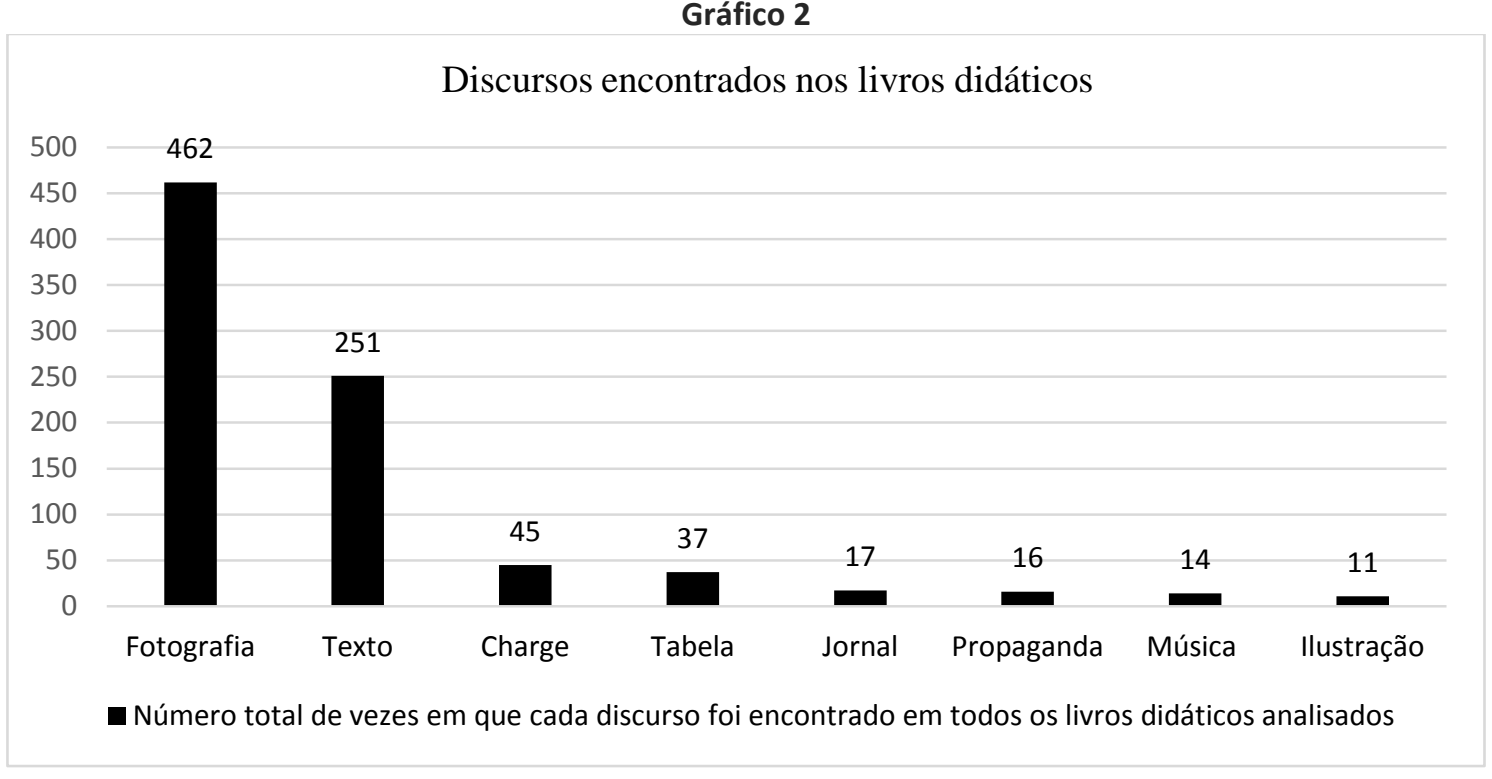

Fonte: Autores (2018).

Pois, as fotografias nos ajudam a compreender a narrativa principal dos livros didáticos. A história que contam se contrapõe àquela presente nos textos. Se no texto principal prevalece a voz de presidentes e as ações do regime, conforme aponta a tabela II, bem como a abordagem que ressalta os aspectos político-econômicos do período, nas fotografias, a realidade é outra. Nas imagens predominam os setores que se opunham à ditadura.

Esse aparente contraste nos ajuda a perceber o modo pelo qual as ações de repressão são abordadas pela narrativa didática. Vejamos com os opositores do regime são representados nas fotografias. Identificamos dezesseis fotografias relacionadas aos opositores - Vladimir Herzog, Carlos Lamarca, Carlos Marighella, Luís Carlos Prestes e Edson Luís ${ }^{5}$. Notamos, ainda, que as fotografias retratam os opositores de duas formas - vivos e mortos. Os retratos da morte são mais frequentes, como aponta o gráfico a seguir.

\footnotetext{
${ }^{5}$ Há um perfil biográfico de cada uma destas personagens em: Araújo, 1995. Para Herzog ver: Almeida Filho, 1986. Para Lamarca, ver: Nogueira, p. 181. Para Marighella: Magalhães, 2012. Para Luís Carlos Prestes: Reis Filho, 2014. Para Edson Luís: Diniz, 1988.
} 
Gráfico 3

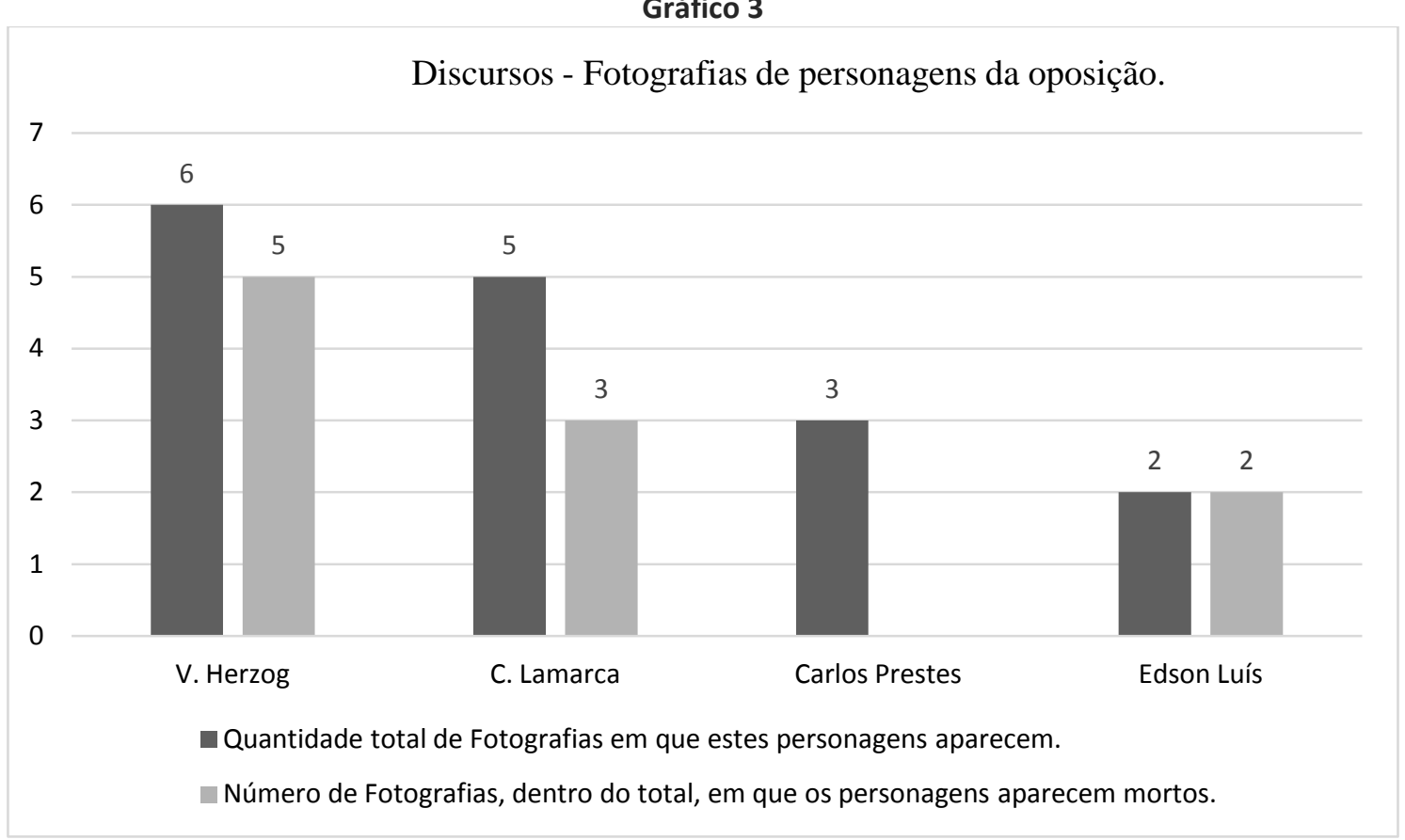

Fonte: Autores (2018).

A ênfase nas fotografias de mortos sugere que, a repressão é percebida como uma ação do regime que se concretiza, fundamentalmente, no assassinato dos opositores. Decorre daí uma característica importante da narrativa: de um lado, a repressão é percebida por meio de uma de suas manifestações mais cruéis, de modo que outras, tão importantes e tão decisivas para a conformação de uma cultura política que ultrapassa o regime, são deixadas de lado; de outro, uma lacuna fica evidente - nos livros didáticos, o lugar da oposição é a cova. Não há preocupação em mostrar quem foram Herzog, Fiel Filho, Edson Luís, Marighella, Lamarca, entre outros, e nem o que estas personagens fizeram, de modo a conformar o panorama de resistência ao regime. A estes agentes normalmente basta, nos textos didáticos, o adjetivo de jornalista, operário, estudante, militante e guerrilheiro - todos eles unidos sob o signo maior de "comunista".

O caso de Edson Luís é exemplar, como vemos em texto de 2006:

Em março de 1968, um pelotão de choque da Polícia Militar invadiu, no Rio de Janeiro, o restaurante apelidado de 'Calabouço', [...]. Os policiais entraram atirando, e uma bala matou o secundarista Edson Luís de Lima Souto, de 18 anos.

Houve [...] revolta da população, após o assassinato.

Milhares de pessoas foram ao enterro ao lado de estudantes que juravam 
ampliar a luta contra o regime, e houve protestos em todo o país. Mas a repressão militar também endureceu... (Anastasia, 2006, pp. 192-193, grifo nosso).

No caso de Vladimir Herzog, nas nove menções ao jornalista o objetivo é destacar seu assassinato em 1975, nas dependências de um quartel do II Exército. Assim, todos os livros analisados buscam mostrar a força que a ditadura exercia contra seus opositores. Neste sentido, a morte de Herzog (como a de Edson e dos outros personagens assassinados) aparece como elemento de articulação da narrativa, cujo foco é a caracterização da força e da brutalidade do regime ditatorial - não as ações das pessoas assassinadas. O livro História: sociedade e cidadania, de 2012, é exemplo:

\footnotetext{
Em outubro de 1975, o jornalista Wladimir Herzog, diretor de jornalismo da TV Cultura, foi chamado a depor em um quartel do II Exército, em São Paulo, por suposta ligação com o Partido Comunista. Ele se dirigiu ao local e, no dia seguinte, apareceu morto em uma cela, asfixiado. Os responsáveis pelos órgãos de repressão disseram que ele cometera suicídio, mas ninguém acreditou nessa versão. A notícia da morte do jornalista chocou a sociedade brasileira. (Boulos JR., 2012, grifo nosso).
}

Este texto de 2012 se destaca muito timidamente dos outros ao acrescentar que Herzog foi chamado a depor "por suposta ligação" com o Partido Comunista. Contudo, a identidade e as ações de Herzog continuam, como nas outras narrativas didáticas, livres de qualquer reflexão.

À oposição política, mesmo quando eleita para compor o quadro de eventos no corpo principal das narrativas didáticas, cabe o papel de coadjuvante. A importância desses personagens parece residir em auxiliar a compor um quadro de crítica à Ditadura. Assim entendemos as escolhas dos autores de obras didáticas ao formularem suas narrativas, pois, elas silenciam sobre as ações dos opositores do Regime - enquanto que as medidas tomadas pelos governos militares são objeto de descrição e de interpretação, as ações dos resistentes são apenas citadas. A ausência de contextualização coloca essas pessoas em situação ambígua: são heróis secundários - o sacrifício de suas vidas os situa como heróis da resistência, mas sua participação efetiva nos processos históricos abordados pela narrativa didática os posiciona como figuras secundárias. Consideramos que sua função na trama é dar sentido a uma narrativa preocupada com as ações do regime, como a violência e arbitrariedade, por exemplo. Suas mortes 
parecem ter muito mais importância para o desenvolvimento desse enredo do que qualquer ação que eles possam ter realizado em vida. Apesar de seus nomes estarem presentes nos livros didáticos, a trajetória e o contexto destes personagens permanecem desconhecidos. Dentre eles, Vladimir Herzog é o mais destacado arauto da oposição nas narrativas didáticas, tanto em números de citações ao longo do texto principal como na incidência em fotografias. Porém, a notícia da qual Herzog é porta-voz é o seu próprio assassinato. Sua morte, em 25 de Outubro de 1975 no DOI-CODI, é utilizada nos textos didáticos como forma de destacar a violência e arbitrariedade do Governo e também como tentativa de explicar o acirramento das ações oposicionistas, a partir da segunda metade da década de 1970.

De todo modo, a historiografia recente tem empreendido esforços no sentido de mostrar quem foram estas figuras que ficaram demarcadas como ícones de resistência à ditadura militar e qual o papel desempenhado por eles nos movimentos de oposição à ditadura. Denise Rollemberg (2007) estuda duas figuras recorrentes das narrativas didáticas: Carlos Marighella e Carlos Lamarca. A autora analisa as diferentes trajetórias desses homens que os levaram ao caminho comum da luta armada, mas que também os distanciaram irremediavelmente por desavenças políticas. No âmbito da resistência civil, o operário Manuel Fiel Filho é lembrado ao lado de Herzog por Mário Sérgio de Morais (2009). O autor utiliza a figura do operário e do jornalista para refletir acerca dos contrastes sociais dentro do movimento oposicionista. Ainda que ambos tenham sido assassinados pelos militares, o autor aponta que suas mortes não tiveram o mesmo grau de repercussão e comoção. Sérgio de Moraes defende que isso ocorre por conta do local social de cada um: Herzog, representante da classe média com visibilidade na mídia e Fiel Filho, operário desconhecido. O estudante Edson Luís é acionado por José Dirceu e Vladimir Palmeira (2003) no capítulo "Mataram um estudante", no livro Abaixo a ditadura: o movimento de 68 contado por seus líderes, no qual os autores contam sobre as alianças estabelecidas entre estudantes, sindicalistas, professores, intelectuais e artistas após a morte de Edson Luís. Angélica Müller (2011) mostra como o Movimento Estudantil (ME) instrumentalizou politicamente os assassinatos de estudantes durante a repressão para utilizá-los como forma de resistência contra o Governo. Neste sentido, a autora estuda a morte do estudante Alexandre Vanucchi Leme, militante da Ação Libertadora Nacional (ALN), e dá destaque também 
à morte do secundarista Edson Luís que, embora morto pelos militares, não era, segundo a autora, um militante engajado contra o Governo. Mesmo assim, o ME soube utilizar a morte de Edson para criar um símbolo de resistência à ditadura.

Essas nuances e características que trazem à tona os diversos matizes dos movimentos de oposição e que permitem observar as semelhanças e dissidências, as contradições e as alianças entre os grupos e indivíduos que compõem a miscelânea da esquerda política brasileira no cenário da ditadura militar não está presente nas narrativas didáticas. A relação entre a narrativa formulada pelos autores de obras didáticas e a produção historiográfica vive, aqui, um descompasso que pode ser percebido em duas dimensões: de um lado, a falta de controle sobre a bibliografia atualizada e sobre os rumos das pesquisas relativas ao período; de outro, a perda da natureza crítica do saber histórico, a qual se volta para a análise das contradições presentes nas relações sociais. A narrativa, antes, parece servir mais à memória que à História - talvez por isso, nelas, a oposição ao regime tem nome e rosto, mas não têm História.

\section{A Resistência e seus contextos}

No inventário dos eventos que compõem o enredo das narrativas didáticas, os movimentos de resistência se referem à Passeata dos Cem Mil, a Campanha pelas Diretas Já e à resistência armada (compreendendo as guerrilhas urbanas e rurais).

\section{Gráfico 4}

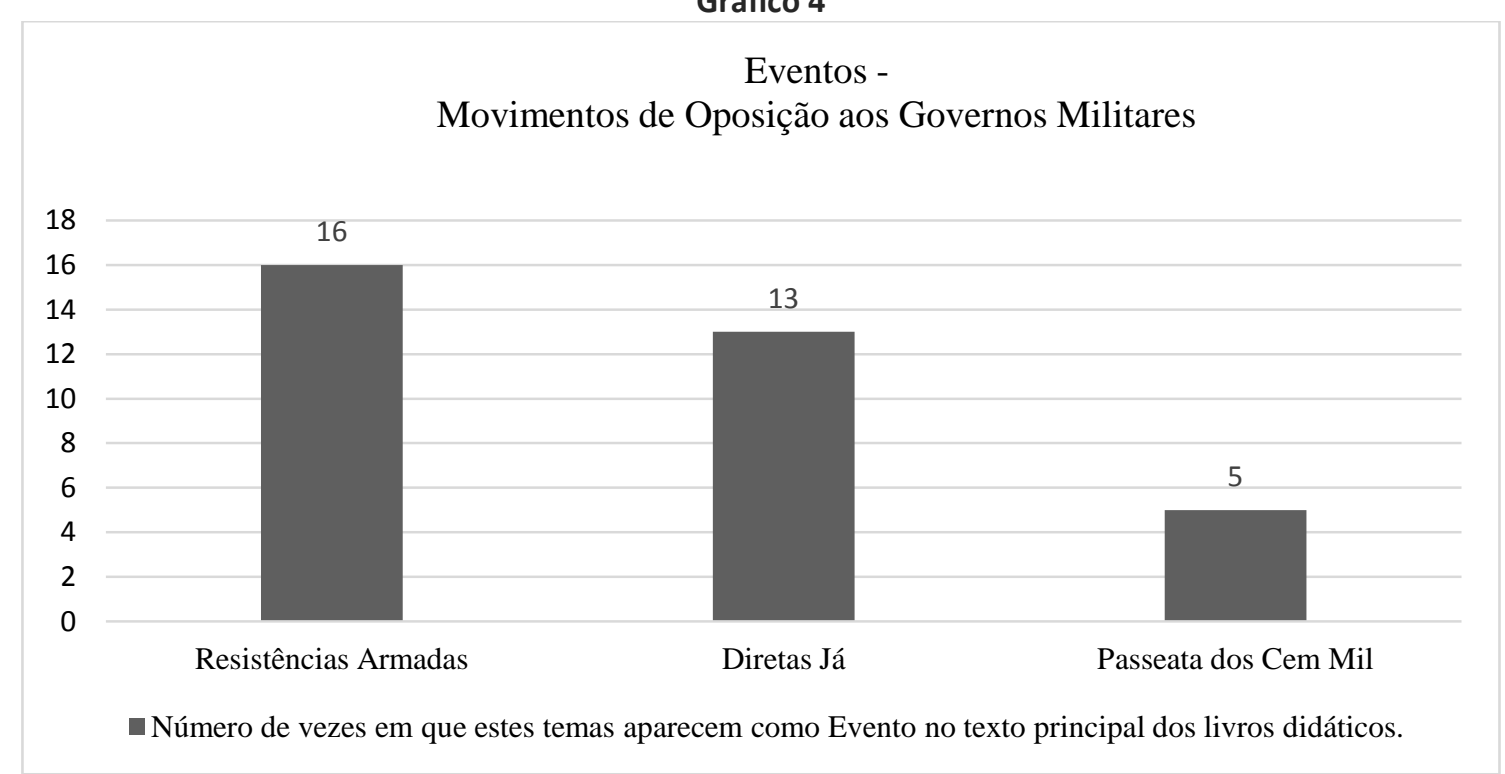


Fonte: Autores (2018)

O gráfico acima evidencia a incidência dos excertos nas coleções estudadas. A resistência armada ao regime é acionada em todas as coleções e a Passeata dos Cem Mil em $1 / 3$ do universo pesquisado. Está claro, então, que a luta armada e a campanha pelo retorno das eleições diretas para presidente conformam os eventos que a narrativa didática elegeu como indicativos da resistência ao regime. Há que se destacar que a escolha destes eventos como índices da oposição à Ditadura deixa de lado outras importantes facetas da resistência, a saber: o movimento estudantil, o movimento operário, as ações de artistas - nas suas mais variadas formas de enfrentamento ao governo -, as articulações políticas da Igreja Católica no combate às arbitrariedades e à violência do Estado, assim como a participação de jornais, desde os de menor porte e circulação aos de maior veiculação no cenário nacional. Estes modelos de resistência não estão suprimidos dos livros didáticos, mas cabe a eles comumente o espaço dos textos paralelos, os boxes [de curiosidade], dando a impressão de que a história deles é uma história dissociada da História, esta contada ao longo do texto principal.

A Passeata dos Cem Mil é vinculada, nas narrativas didáticas, ao assassinato de Edson Luís. A morte do estudante, nestes textos, é descrita como estopim da manifestação de 1968, como podemos observar no texto de 1999: "No Rio de Janeiro, em 1968, mas de 100 mil pessoas saíram à rua em passeata, protestando contra o assassinato de Edson Luís, de 18 nos, pela polícia." (1999, p. 194). E também no texto de 2012, que nos diz que o assassinato de Edson:

...provocou uma onda de protestos, e o maior deles foi a Passeata dos Cem Mil, composta por estudantes, políticos, artistas, trabalhadores e familiares de presos políticos que saíram às ruas do Rio de Janeiro em protesto contra o Regime Militar. (Boulos, 2012, p. 231).

A importância da passeata é afiançada pela literatura que se ocupa do tema. Elio Gaspari diz que a passeata ocorrida a 26 de junho de 1968 “[...] entrou para história das lutas pelas liberdades públicas [...]" e que a "passeata fora a maior vitória conseguida pela oposição desde as eleições de 1965 [...]" (2002, pp. 296-297). José Dirceu e Vladimir Palmeira (2003) contam os acontecimentos que levaram à consolidação da Passeata, bem como seus bastidores - desde a permissão do então governador do Rio 
de Janeiro para que a manifestação ocorresse, esperando a reunião de no máximo cinco mil pessoas, até os receios dos dirigentes estudantis de que houvesse conflito com a polícia. Após a Passeata, algumas pessoas foram presas e, entre os dirigentes do movimento estudantil, formou-se uma comissão especial para tentar negociar com o então presidente Costa e Silva a soltura dos presos, esse episódio foi relatado em detaIhes por Zuenir Ventura (2008).

A Campanha pelas Diretas Já é descrita nos livros didáticos como um importante movimento pelo retorno da democracia. Comumente os autores relatam que todos os setores da sociedade civil participaram da campanha em prol da democracia e pela manutenção de seus direitos políticos, como vemos em 2006:

...todos os setores da sociedade brasileira que faziam oposição se uniram e desencadearam uma campanha nacional em favor das eleições diretas para presidente. Conhecida como a campanha das Diretas Já, foi o movimento popular mais importante no processo de redemocratização do país. (Mello e Costa, 2006, p. 213).

E também em 1993:

\begin{abstract}
Os brasileiros demonstrando uma nova maturidade política, agora lutavam por seu direito de eleger o presidente da república [...] levavam faixas e bandeiras com as palavras de ordem 'Diretas Já', 'Quero Votar para Presidente' e 'Abaixo o Colégio Eleitoral'.

Cantores e artistas de televisão, intelectuais, líderes religiosos e militantes de diferentes partidos políticos, inclusive os que ainda estavam na ilegalidade, como o PCB, PC do B e MR-8, participaram de toda as manifestações. (Valadares, 1993, pp. 174-175, grifo nosso).
\end{abstract}

Além do problema de expressões que não indicam setores da sociedade, nem distinguem suas especificidades, como "todos os setores de oposição" e "os brasileiros" serem generalizações, ainda nos deparamos, no segundo exemplo, com outro problema: os autores não buscam explicar o que eles querem dizer com "demonstrando uma nova maturidade política". Seria oportuno que expusessem o que eles entendem por "maturidade política", permitindo ao estudante refletir sobre a ideia.

De todo modo, esse tipo de explicação sobre as Diretas Já dilui a complexa heterogeneidade política da população brasileira. Neste sentido, Daniel Aarão Reis (2010) já apontava para essa diluição da pluralidade política do Brasil. Como se a multiplicida- 
de política fosse gradualmente se tornando uma coisa só a partir da segunda metade da década de 1970, o autor defende que os setores civis que apoiavam a ditadura parecem ir sumindo das análises sobre a Ditadura até desaparecem por completo, quando se trata da promulgação da Lei da Anistia. O panorama apresentado por Reis se reflete na narrativa didática quando esta trata as campanhas pelas Diretas Já, de 1984, como movimento totalizante de apelo à democracia. Se no texto didático todos os brasileiros queriam realmente o fim da Ditadura, onde foram parar os que a apoiaram?

A mais destacada das formas de oposição à ditadura militar retratada nos livros didáticos como evento são as resistências armadas. Essas aparecem como evento em todos os dezesseis livros didáticos analisados. Nos textos didáticos, esta resistência é citada frequentemente como consequência direta da implantação do Al-5 em 1968. É o que podemos ver nos trechos a seguir apresentados que têm a finalidade de destacar o argumento da resistência armada:

A repressão após a decretação do Al-5 desarticulou os movimentos estudantil e operário. Diante dessa situação, alguns setores da esquerda brasileira recorreram à luta armada para combater o regime, organizando guerrilhas urbanas e rurais. (Braick, 2011, p. 240).

A partir do Al-5 surgiram vários grupos guerrilheiros de esquerda que se lançaram à luta armada em diversas ações: realizaram assalto à banco em busca de dinheiro para financiar a luta política; sequestraram diplomatas estrangeiros para trocá-los por companheiros presos, que estavam sendo torturados nos porões dos órgão de segurança etc. (Cotrim, 1999, p. 195).

O Al-5 tornou as manifestações oposicionistas muito arriscadas, já que os órgãos de repressão passaram aprender sem necessidade de mandado judicial, torturar e até assassinar aqueles que contestassem o governo. [...]. Alguns membros da esquerda, descrentes de uma solução pacífica, aderiram à luta armada. (Mello e Costa, 2006, pp.197-198).

Frequentemente, as narrativas atestam que alguns ou poucos adeptos da esquerda política brasileira aderiram à luta armada que conheceu um rápido fim. Abaixo observamos dois exemplos:

Uma pequena parte da oposição montou organizações guerrilheiras e partiu para a luta armada contra o governo. [...] O governo, porém, reagiu enviando para a região milhares de soldados que liquidaram os focos de guerrilha ali existentes. No final do governo Médici, a guerrilha já tinha sido desmantelada e seus integrantes estavam presos, mortos ou exilados. (Boulos, 2012, p. 232). 
Alguma forças de esquerda concluíram que, naquele momento, não havia outra possibilidade de atuação política e resolveram optar pela luta armada; organizaram-se grupos de guerrilha urbana e rural. [...] Esses e outros grupos não conseguiram o apoio da população e foram dizimados: muitas pessoas foram presas, outras fugiram do país e outras, ainda, foram mortas pela repressão do governo. (Giovanni et al, 1998, p. 253).

Apesar do massivo destaque - presença em todas as narrativas - as análises apresentadas sobre a resistência armada são - em geral - superficiais em função de sua unilateralidade e desconsideração dos contextos nos quais emergiram.

Maria Helena Moreira Alves (2005) após apresentar contextualização política e econômica do período que vai da implantação do Al-5, em dezembro de 1968, até meados da década de 1980, analisa o contexto e as consequências da guerrilha urbana impetrada pela esquerda política brasileira, após o acirramento da repressão em 1968. Já Elio Gaspari (2002) em capítulo intitulado “A floresta dos homens sem alma", discorre sobre o cotidiano dos guerrilheiros no Araguaia, bem como o contato constante destes com os moradores da região, além dos serviços de assistência básica que os guerrilheiros prestavam a eles - como educação, auxílios de saúde, além da participação em trabalhos manuais das comunidades. O autor também mostra com detalhes as campanhas militares que levaram ao fim da guerrilha no Araguaia; pois, esses movimentos de articulação dos guerrilheiros com a população local se perdem na narrativa didática.

Desaparecem também dos textos didáticos as intenções das lutas armadas. Neles, as guerrilhas surgem como um movimento de enfrentamento à Ditadura no sentido de restauração da democracia. Denise Rollemberg (2003) aponta que não foi bem assim. Para ela, as guerrilhas visavam à construção de uma realidade política totalmente nova e diferente da realidade interrompida em 1964.

De todo modo, a escolha dessas formas de resistência como eventos demarcam a resistência à ditadura e implica na supressão de outros segmentos de oposição ao regime que tem sido pormenorizadamente estudado pelo saber historiográfico. No caso dos estudantes, o trabalho de Angélica Müller (2011) é emblemático por ir além da descrição dos atos estudantis frente ao governo, mas por refletir sobre a forma como o Movimento Estudantil conferiu significado aos assassinatos de estudantes, de modo a legitimar a manutenção de uma luta contra o Estado. A complexa, e por vezes 
tensa, relação entre Igreja e Estado no Brasil recrudesce no contexto da ditadura militar. Quem analisa detalhadamente esse processo é Marcio Moreira Alves (1979) que reflete sobre o papel da Igreja Católica no Brasil até chegar ao período da ditadura militar; nessa reflexão mostra o conflito dos interesses do Estado, no contexto do regime, com as intenções da Igreja de lutar por mudanças em uma sociedade injusta e violenta.

Em trabalho de 1999 Maria Aparecida de Aquino (1999) aborda a censura prévia estabelecida a dois jornais de linhas editorias bem diferentes: O Estado de São Paulo e $O$ Movimento. A autora traça o perfil destes periódicos e discorre sobre a história de cada um dos dois. Em seguida, analisa as práticas de censura aplicadas a eles e, paralelamente, demonstra as estratégias de resistência desses jornais. Na literatura didática, no entanto, os jornais são utilizados normalmente como recurso visual (a reprodução de suas páginas), de modo a apresentar uma notícia veiculada por eles, mas sem a preocupação de problematizar ou contextualizar a imprensa e seu papel nos processos de resistência ao regime.

Em livro de 1999, por exemplo, vemos a capa do Jornal do Brasil, sem data, mas podemos inferir o ano de publicação, pois a notícia trata do Al-5. Na capa do jornal lêse "Governo baixa Ato Institucional e coloca Congresso em recesso por tempo ilimitado". A legenda, escrita pelo autor informa: "Manchete do Jornal do Brasil, editado no Rio de Janeiro, noticia o Al-5; o símbolo máximo da legislação autoritária decretada pelo governo militar" (Cotrim, 1999, p. 194). Já o texto de 2009 traz a fotografia da capa do Jornal da Tarde, de 14 de dezembro de 1968. Na manchete pode-se ler "Brasil entra no 5o Ato", "Congresso entra em recesso" e "Entre os presos, Juscelino.". A legenda da fotografia diz o seguinte: "Primeira página do Jornal da Tarde, SP, 14/12/1968" (Rodrigues, 2009, p. 203).

Nota-se que os autores utilizam a reprodução das capas dos jornais como mero recurso ilustrativo. Não há problematização quanto à participação da imprensa, as alianças com o governo vigente ou as dificuldades de se veicular informações de oposição ao regime. As legendas não possibilitam qualquer ação do leitor que não a constatação do que as fotografias registram.

Das formas de resistência não consideradas pelos livros didáticos aquelas produzidas pelas comunidades artísticas talvez sejam as mais emblemáticas. Primeiramen- 
te pela sua ampla diversidade de ação (letras de música, shows, peças teatrais, intervenções de rua, charges etc.) e, em segundo, pelo lugar que é destinado a essas ações na narrativa didática. Elas, com raras exceções, estão ausentes do texto principal para aparecerem em textos paralelos, geralmente sobre os festivais da canção ou letras de música. Dessa forma, a participação política de artistas dos mais variados seguimentos fica deslocada da história apresentada nas coleções didáticas.

Julia Cayses (2014) analisa um tipo de arte surgida entre as décadas de 195060, dentre as quais relembra a obra Situação TE (Trouxas Ensanguentadas) de Artur Barrio, composta por um conjunto de materiais descartáveis e perecíveis envolvidos em sacos de modo a assumir a aparência de corpos humanos. $\mathrm{O}$ artista deixou as peças expostas em um esgoto no Parque Municipal de Belo Horizonte no ano de 1970, auge da ditadura, causando enorme desconforto em quem passava por ali e não fazia ideia de que aquilo era uma obra de arte. A intenção do artista, segundo Cayses (2014), era trazer à luz os assassinatos que ocorriam nos porões da ditadura, principalmente após o Al-5.

Obras como esta não aparecem nas narrativas didáticas. Maria da Conceição Pires (2006) discorre sobre os quadrinhos do cartunista Henfil, mais especificamente sobre os personagens Fradin. A autora identifica um padrão de crítica ao autoritarismo do Estado e ao moralismo e costumes da classe média por meio destes personagens de Henfil. Nos textos didáticos as charges e os cartuns não passam por esse processo de reflexão - como jornais e revistas - sendo, no mais das vezes, utilizados mais como mera ilustração.

Literatura acadêmica mais fecunda sobre a resistência artística é aquela sobre músicas e festivas da canção ${ }^{6}$. Marcos Napolitano (2003), historiador dessa temática, aborda o assunto em diversos prismas, como a análise de músicas de Chico Buarque que permite entender as várias críticas presentes nas letras do compositor sobre a opressão do Estado em um contexto de autoritarismo instituído. Napolitano (2004) procura entender a lógica dos agentes da repressão sobre a MPB de 1968 a 1981. Em outro trabalho, ele aponta como a MPB foi um importante instrumento de expressão da esquerda política brasileira, desde os anos 1960, e como ela se tornou porta-voz da abertura política que se deu a partir da segunda metade de 1970, passando pela pro-

${ }^{6}$ Ver por exemplo: Favaretto, 2000; Mello, 2003; Vilarino, 2006. 
mulgação da Anistia em 1979, e chegando ao início dos anos 1980 (2010). Todos esses matizes referentes ao cenário musical, bem como sobre cantores e compositores ativos durante a ditadura militar, são resumidos, nas narrativas didáticas em trechos de canções ou pequenos perfis biográficos de um ou outro artista.

\section{Considerações}

É notável que a escrita da história do Brasil Republicano advém de uma longa tradição que privilegia as perspectivas econômica e político-administrativa e isso se reflete nas narrativas didáticas. Todavia, como demonstramos, a historiografia recente vem apresentando novos redimensionamentos para a análise deste período, inclusive no contexto da ditadura. A história econômica tem saído de cena e, ainda que a perspectiva político-administrativa persista em muitos trabalhos, nota-se uma predominância da história social e cultural, onde se procura dar voz a outros personagens, no contexto da ditadura, para além dos políticos e presidentes. Setores e personagens de oposição têm recebido cada vez mais atenção e espaço na produção historiográfica. Contudo, nas narrativas didáticas, ainda que tenha havido mudanças desde a década de 1990, ainda há muito que se fazer quanto à forma de se estruturar a narrativa. Sendo verdade que os setores sociais e de oposição à ditadura têm conquistado mais espaço nas narrativas didáticas, nas últimas décadas, também é verdade que a forma como estes segmentos aparecem não favorece seu protagonismo. Relegados a boxes de curiosidade e textos paralelos, a história da oposição adquire características de um apêndice da História que, é retratada ao longo do texto principal das narrativas didáticas.

\section{FONTES}

ANASTASIA, Carla; RIBEIRO, Vanise. Encontros com a história: 8a série. Curitiba: Positivo, 2006.

APOLINÁRIO, Maria Raquel. Projeto araribá: história/organizadora Editora Moderna; obra coletiva desenvolvida e produzida pela Editora Moderna; editora responsável Maria Raquel Apolinário. 2. ed. São Paulo: Moderna, 2007.

BOULOS Jr. Alfredo. História: sociedade e cidadania 9 ano. 2. ed. São Paulo: FTD, 2012.

BOULOS Jr., Alfredo. História do Brasil: Império e República, volume 2. São Paulo: FTD, 
1995.

BRAICK, Patrícia Ramos. Estudar história: das origens do homem à era digital. 1. ed. São Paulo: Moderna, 2011.

CAMPOS, Flávio de; CLARO, Regina; DOLHNIKOFF, Mirian. História nos dias de hoje, 9 은 ano. São Paulo: Leya, 2012.

CARMO, Sonia Irene Silva do; COUTO, Eliane Frossard Bittencourt. História: passado presente; 4 - a expansão Imperialista e o Brasil República. São Paulo: Atual, 1997.

COTRIM, Gilberto. Saber e fazer história, 8a série. São Paulo: Saraiva, 1999.

GIOVANNI, Maria Cristina Visconti; JUNQUEIRA, Zilda Almeida; TUONO, Silvia Guena. História: compreender para aprender, 8. São Paulo: FTD, 1998.

MACEDO, José Rivair; OLIVEIRA, Mariley W. Brasil: uma história em construção. São Paulo: Editora do Brasil, 1996.

MELLO, Leonel Itaussu de A.; COSTA, Luís César Amad. Construindo consciências: história, 8. a série. 1. ed. São Paulo: Scipione, 2006.

MOCELLIN, Renato; CAMARGO, Rosiane de. Projeto apoema história 9.1. ed. São Paulo: Editora do Brasil, 2013.

MOCELLIN, Renato. Brasil: para compreender a história, 6a série. São Paulo: Editora do Brasil, 1997.

MOCELLIN, Renato. Brasil: para compreender a história, volume 1. São Paulo: Editora do Brasil, 1997.

RODRIGUES, Joelza Ester Domingues. História em documento: imagem e texto, 9o ano. ed. renovada. São Paulo: FTD, 2009.

VALADARES, Virgínia Trindade; RIBEIRO, Vanise; MARTINS, Sebastião. História: assim caminha a humanidade ${ }^{a}$ a série. Belo Horizonte: Editora do Brasil em Minas Gerais, 1993.

\section{REFERÊNCIAS}

ALMEIDA, Adjovanes T. S. de. O regime militar nos livros didáticos: os acontecimentos de 1968. Encontros, Ano 10, Número 19. P. 10-20 - 2o semestre 2012.

ALMEIDA, Valesca de Souza. A luta armada através dos livros didáticos. Revista Contemporânea, ano 4, n. 5, vol. 1, 2014.

ALVES, Marcio Moreira. A Igreja e a Política no Brasil. 1979. São Paulo, Editora Brasiliense.

ALVES, Maria Helena Moreira. Estado e oposição no Brasil (1964-1984). Bauru, SP: Edusc, 2005.

AQUINO, Maria Aparecida de. Censura, imprensa, Estado autoritário (1968-1978): o exercício cotidiano da dominação e da resistência O Estado de São Paulo e Movimento. Bauru: Edusc, 1999.

ARAÚJO, Maria do Amparo Almeida. Dossiê dos mortos e desaparecidos políticos a partir de 1964. - Recife: Companhia Editora de Pernambuco, 1995.

ASSUNÇÃO, Cristina Adelina de. A ditadura militar retratada nos livros didáticos de história do Brasil de 1964 a 1985. São Paulo: PUC, 2009. Dissertação (Mestrado) - Mestrado em História Social, Pontifícia Universidade Católica de São Paulo, São Paulo, 2009.

CAYSES, Julia Buenaventura Valencia de. Isto não é uma obra: arte e ditadura. Estudos avançados 28 (80), 2014. 
COELHO, Mauro Cezar. Que enredo tem essa história? A colonização portuguesa na América nos livros didáticos de história. In: ROCHA, Helenice; REZNICK, Luis; MAGALHÃES, Marcelo de Souza (Org.). Livros didáticos de história: entre políticas e narrativas. Rio de Janeiro: FGV Editora, 2017.

DINIZ, Josué. O cerco das trevas: calabouço - 1968. Rio de Janeiro: Achiamé, 1988.

DIRCEU, José; PALMEIRA, Vladimir. Abaixo a ditadura: o movimento de 68 contado por seus líderes. Rio de Janeiro: Espaço e Tempo: Garamond, 2003.

FAVARETTO, Celso. Tropicália, alegoria, alegria. 3.ed. São Paulo: Ateliê Editorial, 2000. FERREIRA, Marieta de Morais; FRANCO, Renato. Desafios do ensino de história. Estudos Históricos, Rio de Janeiro, vol. 21, nㅇ4 41, janeiro-junho de 2008. P.79-93.

FRAGA, André Barbosa. As representações sobre o regime militar nos livros didáticos de história (1985-2011): de "revolução" a golpe civil-militar de 1964. Enfoques Vol.13 (2) Dezembro, 2014.

GASPARI, Elio. As ilusões armadas: A ditadura envergonhada. São Paulo: Companhia das Letras, 2002.

HORIKAWA, Alice Yoko; JARDILINO, José Lima. A formação de professores e o livro didático: avaliação e controle dos saberes escolares. Revista Lusófona de Educação, 15, 147-162. 2010

JOSÉ, Emiliano; MIRANDA, Oldack. Lamarca, o capitão da guerrilha. 12ª ed. São Paulo: Global Editora, 1989

MAGALHÃES, Mário. Marighella: o guerrilheiro que incendiou o mundo, 1 a ed. São Paulo: Companhia das Letras, 2012.

MELLO, Zuza Homem de. A Era dos Festivais: uma parábola. São Paulo: Ed. 34, 2003.

MIRANDA, Sonia Regina; LUCCA, Tânia Regina. O livro didático de história hoje: um panorama a partir do PNDL. Revista Brasileira de História. São Paulo, v. 24, № 48, 2004. MORAES, Mário Sérgio de. Memória e Cidadania: as mortes de V. Herzog, Manuel F. Filho e José F. de Almeida. In: Desarquivando a ditadura: memória e justiça social no Brasil, volume I / Cecília MacDowell Santos, Edson Teles, Janaína de Almeida Teles (orgs.). São Paulo: Aderaldo e Rothschild Editores, 2009.

MÜLLER, Angélica. "Você me prende vivo, eu escapo morto": a comemoração da morte de estudantes na resistência contra o regime militar. Revista Brasileira de História. São Paulo, v. 31, no 61, p. 167-184, 2011.

MUNAKATA, Kazumi. O livro didático como mercadoria. Pro-posições. V. 23, N. 3 (69). p. 51-66. Set./Dez. 2012

NAPOLITANO, Marcos. "Hoje preciso refletir um pouco": ser social e tempo histórico na obra de Chico Buarque de Hollanda - 1971/1978. História, São Paulo, 22 (1): 115134, 2003.

NAPOLITANO, Marcos. A MPB sob suspeita: a censura musical vista pela ótica dos serviços de vigilância política (1968-1981). Revista Brasileira de História. São Paulo, v. 24, no 47, p.103-126 - 2004.

NAPOLITANO, Marcos. MPB: a trilha sonora da abertura política (1975/1982). Estudos Avançados 24 (69), 2010.

NOGUEIRA, Jefferson Gomes. Carlos Lamarca no imaginário político brasileiro: o papel da Imprensa na construção da imagem do "Capitão Guerrilheiro". In: Revista Ágora, n. 7. Vitória: Universidade Federal do Espírito Santo, p. 1-28, 2008.

NOGUEIRA, Jefferson Gomes. Carlos Lamarca: o militar guerrilheiro (1969-1971). Dissertação (Mestrado em História) - Universidade Federal do Espírito Santo, Centro de 
Ciências Humanas e Naturais. Vitória, 2009. p. 181.

PATRIOTA, Rosangela. A cena tropicalista no Teatro Oficina de São Paulo. História, São Paulo, 22 (1): 135-163, 2003.

PEREIRA, Mateus H. F. e PEREIRA, Andreza C. I. Os sentidos do Golpe de 1964 nos livros didáticos de história (1970-2000): entre continuidades e descontinuidades. Tempo, vol.16, n.30, pp.197-220, 2011. Disponivel em: <http://www.scielo.br/scielo.php?pid= S1413-77042011000100009\&script=sci_abstract\&tlng=pt>. Acesso em 20 de março de 2018.

PIRES, Maria da Conceição Francisca. Cultura e política nos quadrinhos de Henfil. História, São Paulo, v. 25, n. 2 p. 94-114, 2006.

REIS FILHO, Daniel Aarão. Luís Carlos Prestes: um revolucionário entre dois mundos. São Paulo: Companhia das Letras, 2014.

REIS, Daniel Aarão. Ditadura, anistia e reconciliação. Estudos Históricos, Rio de Janeiro, vol. 23, no 45, p. 171-186, janeiro-junho de 2010.

ROCHA, Aristeu Castilhos da. O regime militar no livro didático de história do ensino médio: a construção de uma memória. 2008 Tese (Doutorado em História) - Pontifícia Universidade Católica do Rio Grande do Sul, Programa de Pós-Graduação em História, Porto Alegre, 2008.

ROCHA, Helenice; CAIMI, Flávia. A(s) história(s) contada(s) nos livros didático hoje: entre o nacional e o mundial. Revista brasileira de História. São Paulo. V.34, no 68, 2014.

ROLLEMBERG, Denise. Carlos Marighella e Carlos Lamarca: memórias de dois revolucionários. In: FERREIRA, Jorge; AARÃO REIS, Daniel (orgs.). As esquerdas no Brasil. Revolução e democracia. Vol. 3. 1964... Rio de Janeiro: Civilização Brasileira, 2007.

ROLLEMBERG, Denise. Esquerdas revolucionárias e luta armada. In: FERREIRA, Jorge; DELGADO, Lucília de Almeida Neves. (Orgs.). O Brasil republicano - o tempo da ditadura: regime militar e movimentos sociais em finais do século XX. Rio de Janeiro: Civilização Brasileira, 2003, pp. 43-91.

SILVA, Marco Antônio. A fetichização dos livros didáticos. Educação Realidade, Porto Alegre, v. 37, n. 3, p. 803-821, set./dez. 2012

VENTURA, Zuenir. 1968: o ano que não terminou. São Paulo: Editora Planeta do Brasil, 2008.

VILARINO, Ramon Casas. A MPB em movimento: música, festivais e censura. São Paulo: Olho d'Água, 2006.

ZAMBON, Luciana Bagolin; TERRAZZAN, Eduardo Adolfo. Políticas de material didático no Brasil: organização dos processos de escolha de livros didáticos em escolas públicas de educação básica. Rev. Bras. Estud. Pedagog., Brasília, v. 94, n. 237, p. 585-602, ago. 2013. Disponível em: <http://www.scielo.br/scielo.php?script=sci_arttext\&pid=S2176$66812013000200012 \&$ Ing=en\&nrm=iso>. Acesso em: 20 mar. 2018. 